OPEN ACCESS

Edited by:

Alfonso Jiménez,

University of Alicante, Spain

Reviewed by:

Debora Puglia

University of Perugia, Italy

Pawet Chmielarz,

Rzeszów University of Technology,

Poland

*Correspondence:

Mariana Fornazier

mariana-for@hotmail.com

Harumi Otaguro

harumi.otaguro@ufu.br

Specialty section:

This article was submitted to

Periodontics,

a section of the journa

Frontiers in Dental Medicine

Received: 14 September 2021 Accepted: 29 November 2021 Published: 22 December 2021

Citation:

Fornazier M, Gontijo de Melo P,

Pasquini $D$, Otaguro H, Pompêu GCS and Ruggiero $R$ (2021) Additives Incorporated in Cellulose Acetate

Membranes to Improve Its

Performance as a Barrier in

Periodontal Treatment.

Front. Dent. Med. 2:776887. doi: 10.3389/fdmed.2021.776887

\section{Additives Incorporated in Cellulose Acetate Membranes to Improve Its Performance as a Barrier in Periodontal Treatment}

\author{
Mariana Fornazier ${ }^{1 *}$, Patricia Gontijo de Melo ${ }^{2}$, Daniel Pasquini ${ }^{1}$, Harumi Otaguro ${ }^{1 *}$, \\ Gabriela Ciribelli Santos Pompêu ${ }^{1}$ and Reinaldo Ruggiero ${ }^{1}$ \\ ${ }^{1}$ Chemistry Department, Institute of Chemistry, Federal University of Uberlândia, Uberlândia, Brazil, ${ }^{2}$ Institute of Chemistry, \\ Federal Institute of Education, Science Technology of the Triângulo Mineiro, Uberaba, Brazil
}

In this study, we prepared cellulose acetate membranes, by means of casting mold, incorporated with two additives, sodium carboxymethyl lignin and calcium glycerophosphate, in order to improve properties for periodontal applications. The membranes were characterized from the morphological, structural, thermal and mechanical point of view, as well as by physiological $\mathrm{pH}$ tests. The results showed that membranes with additives improve the physical-chemical and mechanical properties, especially when the two additives are present in the same membrane, which can be attributed to the important synergy between them. The most significant effects occur in increasing the thickness and decreasing the density, which reflects in the porosity of the membranes, although the added amounts do not exceed $1.4 \%$. A $1 \%$ increase in lignin concentration does not change the thickness and density of the membrane, but that amount of lignin plus $0.4 \%$ calcium glycerophosphate increases the thickness of the membrane by $42 \%$ and decreases the density by about $6 \%$. Although there is a decrease in mechanical properties, as observed in Young's modulus and crystallinity, the significant and intermittent increase in sample weight loss with both additives in physiological solution indicates that, in the long run, it can be used as a degradable barrier.

Keywords: membranes, cellulose acetate, additions, dental barrier, hydrophilia

\section{INTRODUCTION}

Periodontal disease is an infectious disease, induced by microorganisms present in the bacterial plaque, which attack the periodontal tissues, resulting in tooth loss $(1,2)$. The traditional procedure used to repair damaged tissues consists of surgical procedures and mechanical debridement (i.e., scaling and root planing), which allows the healing of periodontal defects $(3,4)$. However, depending on the size of the defect, complete regeneration of periodontal tissues becomes difficult [4]. Thus, regenerative approaches such as guided tissue/bone regeneration (GTR/GBR) have emerged as the most widely practiced periodontal regeneration procedure $(4,5)$. The principle of GTR/GBR consists in the use of a membrane that acts as a physical barrier, creating a suitable environment for regeneration, protected from the competitive invasion of less differentiated cells and highly proliferative cells of the surrounding tissue, mainly fibroblasts and epithelial cells. In addition, the original cell proliferation characteristics of the natural regeneration region should be promoted $(6,7)$. 
Several factors should be considered when using membranes as a physical barrier, such as: biocompatibility, cellular occlusion (thus allowing selective cell migration), tissue integration, immunological neutrality, capacity to promote and maintain the space to allow a stable volume during the repair period and easy manipulation $(4,7)$. In addition, the membrane must withstand the forces exerted by the chewing process and the tissue flap tension, preventing membrane collapse and have a known degradation rate (7).

Commercial barrier membranes are produced out of materials which are either non-resorbable and require a second surgery for removal or made from resorbable materials (8). Among the materials used for the development of membranes used as a physical barrier in the GTR, cellulose acetate (CA) was the first non-absorbable material to be used (6) due to the following properties: is a neutral polymer, has the ability to form transparent films, is biocompatible, has a low cost and is obtained from cellulose, a natural and renewable polymer (9). In addition, the physical and chemical properties of the CA membranes can be altered adding to it beneficial functions for the regeneration process $(10,11)$.

Degradability is one of the most important aspects involved in the clinical success of GTR/GBR membranes and strongly depends on the type of polymeric system used, with hydrophobic systems exhibiting less degradability (7). Cellulose acetate is a polymer with known degradability and hydrophobic characteristics, and as one property influences the other, it has a low degradation rate (9). Studies use the strategy of mixing polymers with functional additives to ensure greater degradability and hydrophilicity, as well as favoring membrane interaction with the oral environment $(12,13)$.

In this study, we prepared three types of cellulose acetate membranes, one pure (CA). The second, incorporated with sodium carboxymethyl lignin (CA- $\mathrm{NaCML}$ ), and the third with this additive plus calcium glycerophosphate (CA-NaCML$\mathrm{CaGP}$ ). The first (NaCML) is a macroelectrolyte derived from sugarcane bagasse lignin, soluble in water at $\mathrm{pH}>$ 4, the second one ( $\mathrm{CaGP})$, is an electrolyte containing Glycerol bound to calcium phosphate. Lignin is one of the components of superior vegetables that confer properties, among others, such as: antioxidant agent and nutrient propagation channels from the root to the leaves. The adoption of this component (NaCML) as one of the CA fillers should facilitate the transport of nutrients, which facilitates periodontal recomposition. Furthermore, modified (carboxymethylated) lignin, in turn, even in very small amounts, imposes an important reinforcement in the structure of cellulose acetate (11).

CaGP incorporation increases cell adhesion, proliferation, and metabolic activation since calcium phosphate $(\mathrm{CaP})$ based materials are biocompatible, bioactive and osteoconductive $(12,14)$. Some studies have demonstrated bone regeneration $(7,15)$ and good control over the rate of membrane degradation (16) when $\mathrm{CaP}$ is incorporated into the polymeric material. Moreover, the incorporation of both additives gives greater hydrophilia to the membrane, favoring their interaction with the oral environment. The membranes have also been evaluated for their potential use as dental barrier device by their
TABLE 1 | Formulation used for the preparation of the membranes.

\begin{tabular}{lcccc}
\hline Membrane & $\begin{array}{c}\text { Mass } \\
\mathbf{C A} \\
\mathbf{( g )}\end{array}$ & $\begin{array}{c}\text { Mass NaCML } \\
\mathbf{( g )}\end{array}$ & $\begin{array}{c}\text { Mass CaGP } \\
\mathbf{( g )}\end{array}$ & $\begin{array}{c}\text { Volume of water/ } \\
\text { acetone (8:2 v/v) } \\
(\mathbf{m l})\end{array}$ \\
\hline CA & 10.000 & - & - & 100.00 \\
CA-CML & 9.900 & 0.100 & - & 100.00 \\
CA-CML- CaGP & 9.860 & 0.100 & 0.040 & 100.00 \\
\hline
\end{tabular}

physical and chemical characteristics obtained from structural, morphological, thermal and mechanical characterization techniques and also by physiological $\mathrm{pH}$ tests.

\section{MATERIALS AND METHODS}

\section{Materials}

Cellulose acetate $\left(\mathrm{CA}, \mathrm{Mw}=30.000 \mathrm{~g} \mathrm{~mol}^{-1}\right)$ and Calcium glycerophosphate (CaGP, $\mathrm{Mw}=210.14 \mathrm{~g} \mathrm{~mol}^{-1}$ ) purchased from Sigma-Aldrich (St. Louis, MO, USA), Sodium carboxymethyl lignin $(\mathrm{NaCML})$, produced, by a method developed in our laboratory-Industrial Crops and Products 36 (17) 108-115 and Acetone 99.5\% (VETEC).

Phosphate-buffered saline solution (PBS) was prepared by mixing Sodium hydroxide (Vetec), Dihydrogen sodium phosphate (Carlo ErbaReagents) and Deionized water.

\section{Preparation of the Membranes}

The membranes were prepared by the casting method, developed in our laboratory (9), so that the final concentration of the membranes was $10 \%(\mathrm{w} / \mathrm{v})$, with variation of the CA mass by incorporation of the additives, as shown in Table $\mathbf{1}$.

The systems containing the formulations described in Table 1 were subjected to magnetic stirring for a period of $24 \mathrm{~h}$ for total solubilization. Then, the film-forming solutions obtained were dispersed, with the aid of an adjustable film spreader, inside a glass box, where they remained until total evaporation of the solvent. After drying, the formed membranes were stored in a desiccator.

\section{Characterization}

\section{Measurement of Membranes Thickness and Density}

The membranes were cut (area: $1 \mathrm{~cm}^{2}$ ) and then dried in an oven at $60^{\circ} \mathrm{C}$ for $2 \mathrm{~h}$, for removal of any moisture and weighed on an analytical balance. Subsequently its thickness was determined in five different points, using a ZAAS digital micrometer.

The density $(\mathrm{d})$ was calculated from Equation (1), where "m" is the mass of the film, " $\mathrm{t}$ " the thickness $(\mathrm{cm})$ of the sample and "A" the area of the sample (18).

$$
d=\frac{m}{V}=\frac{m}{t A}
$$

\section{Scanning Electron Microscopy}

The morphology of the membranes was analyzed in relation to their surface and transversal section using the CARL ZEISS MOD EVO MA10 microscope, with an acceleration voltage of $5 \mathrm{kV}$. 
Prior to analysis, the samples were coated with an ultrathin gold layer in a sputter coating system.

\section{X-Ray Diffraction}

X-ray diffraction analysis was performed on a Shimadzu XRD6000 apparatus (Shimadzu, Japan), operating at a power of $40 \mathrm{kV}$ with $3 \mathrm{~mA}$ of current and $\mathrm{Cu} \mathrm{K} \alpha$ radiation $(1.5406 \dot{\mathrm{A}}$ ). The $2 \theta$ scan data were collected from $5^{\circ}$ to $37^{\circ}$ at a scanning speed of $2.0^{\circ} \mathrm{min}^{-1}$.

\section{Differential Scanning Calorimetry}

The analyzes were performed on a Q-20 (TA Instruments, New Castle, DE, USA) apparatus using about $7 \mathrm{mg}$ of sample at a heating rate of $10^{\circ} \mathrm{C} \mathrm{min}^{-1}$ from $25^{\circ} \mathrm{C}$ to $400^{\circ} \mathrm{C}$, under nitrogen atmosphere with flow of $50 \mathrm{~cm}^{3} \mathrm{~min}^{-1}$.

The calculation of the degree of crystallinity was based on the melting enthalpy of $100 \%$ crystalline cellulose acetate, $58.8 \mathrm{~J} \mathrm{~g}^{-1}$, determined by Cerqueira et al. (19).

\section{Mechanical Properties}

The mechanical properties (i.e., tensile strength, Young's modulus, and elongation at break) of all the membranes were evaluated by uni-axial tensile testing using a universal Instron mechanical test machine model 5,982, with a $5.0 \mathrm{kN}$ load cell. The membranes were cut into strips $0.5 \mathrm{~cm}$ wide by $2.6 \mathrm{~cm}$ long, fixed in the apparatus and subjected to stress and strain test with a velocity of $2.0 \mathrm{~mm}$ min-1 and distance between the claws of $1.6 \mathrm{~cm}$. The sample thickness was determined by measuring with calipers at five locations. Mechanical parameters were obtained from the stress-strain measures of each sample and expressed in MPa. The results and standard mean deviation (SD) was reported.

\section{Swelling and Degradation Studies at Physiological pH}

The swelling and degradation studies were carried out under conditions that simulate the oral environment, obtained using a phosphate buffered saline solution (PBS), whose $\mathrm{pH}=7.4$ is similar to the physiological $\mathrm{pH}$ of the blood $(\mathrm{pH}=7.35)$ :

The swelling was evaluated in PBS medium by a gravimetric method (15). The membranes were weighed $\left(\mathrm{W}_{\mathrm{d}}\right)$ and then immersed in $10 \mathrm{ml} \mathrm{PBS}$ at $36.5^{\circ} \mathrm{C}$. At different times periods, the samples were removed from the PBS, gently wiped with filter paper to remove the surface liquid and immediately weighed $\left(\mathrm{W}_{\mathrm{w}}\right)$. The dilation ratio of the membranes was calculated using Equation (2):

$$
\text { Swelling ratio }(\%)=\frac{W_{w}-W_{d}}{W_{d}} \times 100
$$

For degradation studies, dry membranes samples were weighed $\left(\mathrm{W}_{\mathrm{i}}\right)$, than then immersed in PBS and incubated in a bath at $36.5^{\circ} \mathrm{C}$ for several weeks. The PBS solution was renewed after every analyses and at each time interval samples were dried before weighing $\left(\mathrm{W}_{\mathrm{f}}\right)$. Weight loss was calculated by using the Equation (2) (15):

$$
\text { Weight loss }(\%)=\frac{W_{i}-W_{f}}{W_{i}} \times 100
$$

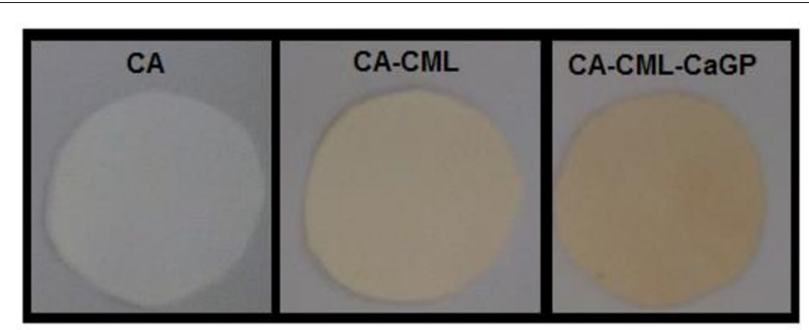

FIGURE 1 | Photo of membranes produced.

TABLE 2 | Thickness and density of the membranes.

\begin{tabular}{lcc}
\hline Sample & $\begin{array}{c}\text { Thickness } \\
\mathbf{( m m})\end{array}$ & $\begin{array}{c}\text { Density } \\
\left(\mathbf{g} \mathbf{~ c m}^{-3} \mathbf{)}\right.\end{array}$ \\
\hline $\mathrm{CA}$ & $0.135 \pm 0.002$ & $0.420 \pm 0.009$ \\
$\mathrm{CA-NaCML}$ & $0.133 \pm 0.003$ & $0.417 \pm 0.005$ \\
CA-NaCML-CaGP & $0.235 \pm 0.004$ & $0.394 \pm 0.006$ \\
\hline
\end{tabular}

\section{RESULTS}

\section{Preparation of the Membranes, Thickness and Density}

The membranes were produced by the casting method, resulting in opaque, flexible samples without bubbles or fissures (Figure 1). The thickness and density data are presented in Table 2. It is interesting to note that despite the small amounts of additives in the membranes, its effect on these two properties was quite significant. Note that the NaCML additive did not cause any significant changes, whereas the addition of only $0.040 \mathrm{~g}$ of the CaGP additive in $9.860 \mathrm{~g}$ of cellulose acetate, about $0.4 \%$, causes an increase in the membrane of about $43 \%$ in thickness and about $5 \%$ in the decrease in density.

\section{Scanning Electron Microscopy}

The morphological characteristics of the membranes were analyzed by SEM in order to investigate the general aspects of the surface and its transversal cross-section, as can be seen in Figure 2. From the micrographs it can be seen that the membranes shows pores on their surface and along its crosssection. Moreover, they reveal that the pores have irregular sizes and distribution in regions of different densities. When compared, the membranes with additives present an increase in porosity, best observed in micrographs of transversal cross sections, caused by its interaction in the cellulose acetate matrix. The average pore diameter, determined by the scale of the micrographs, increased from $1.50 \pm 0.52 \mathrm{~nm}$ in the CA to 3.33 \pm 1.07 in the CA-NaCML membrane and $3.83 \pm 1.34$ in the CA-NaCML- CaGP.

\section{X-Ray Diffraction Analysis}

The diffractograms of the membranes are shown in Figure 3. The peaks seen in $2 \theta$ angles $\approx 8.5^{\circ} ; 10.5^{\circ} ; 13.5^{\circ} ; 17.5^{\circ}$ and 


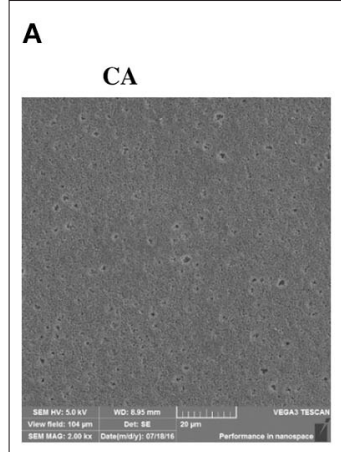

B

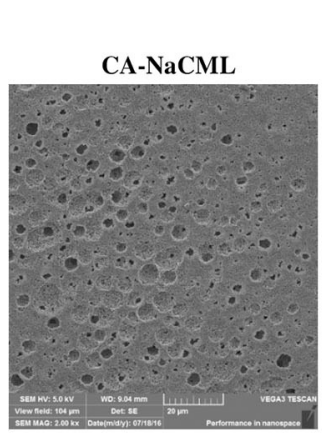

CA-NaCML-CaGP

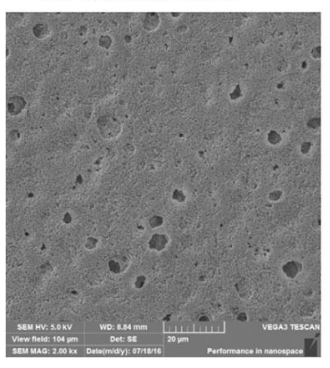

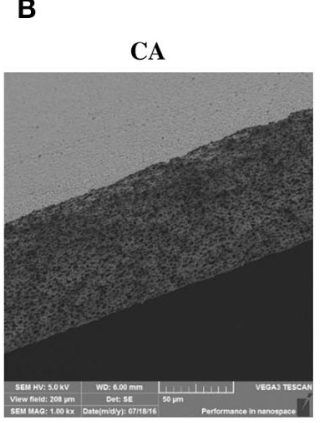

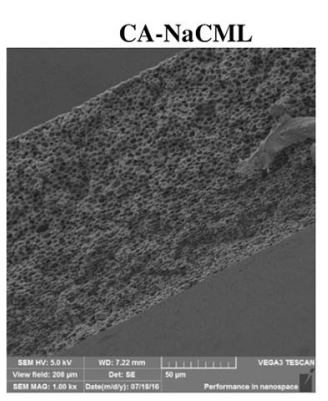

CA-NaCML-CaGP

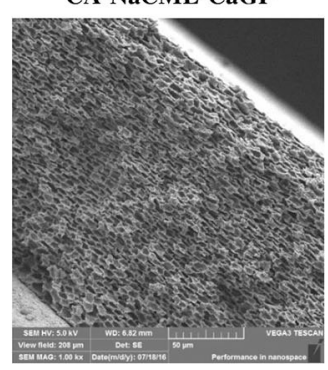

FIGURE 2 | Microscopy images of (A) surface and (B) transversal cross-section of membrane.

$22^{\circ}$, corresponding to the cellulose acetate structure (20). The incorporation of the additives to the membranes resulted in an increase in the structural order of the matrix, with intensification of the diffraction peaks, mainly in the simultaneous presence of the two additives. This effect should be the result of an increase in the crystallinity of the acetate matrix due to the presence of the additives. An estimate of the crystallinity indices (Icr) of the membranes, determined by the Lorentz equation, shows this effect, where the Icr varies from 1.17 for $\mathrm{CA}$, to 1.50 for CA-NaCML, to 1.87 for CA-NaCML-CaGP in kcps* deg.

\section{Differential Scanning Calorimetry}

The DSC results of the membranes (Figure 4) were used to determine the differences in the thermal behavior of the materials. The two endothermic signals for all membranes are assigned the solvent output of the matrix structure, which occurs between 30 and $120^{\circ} \mathrm{C}$, and to the melting followed by the
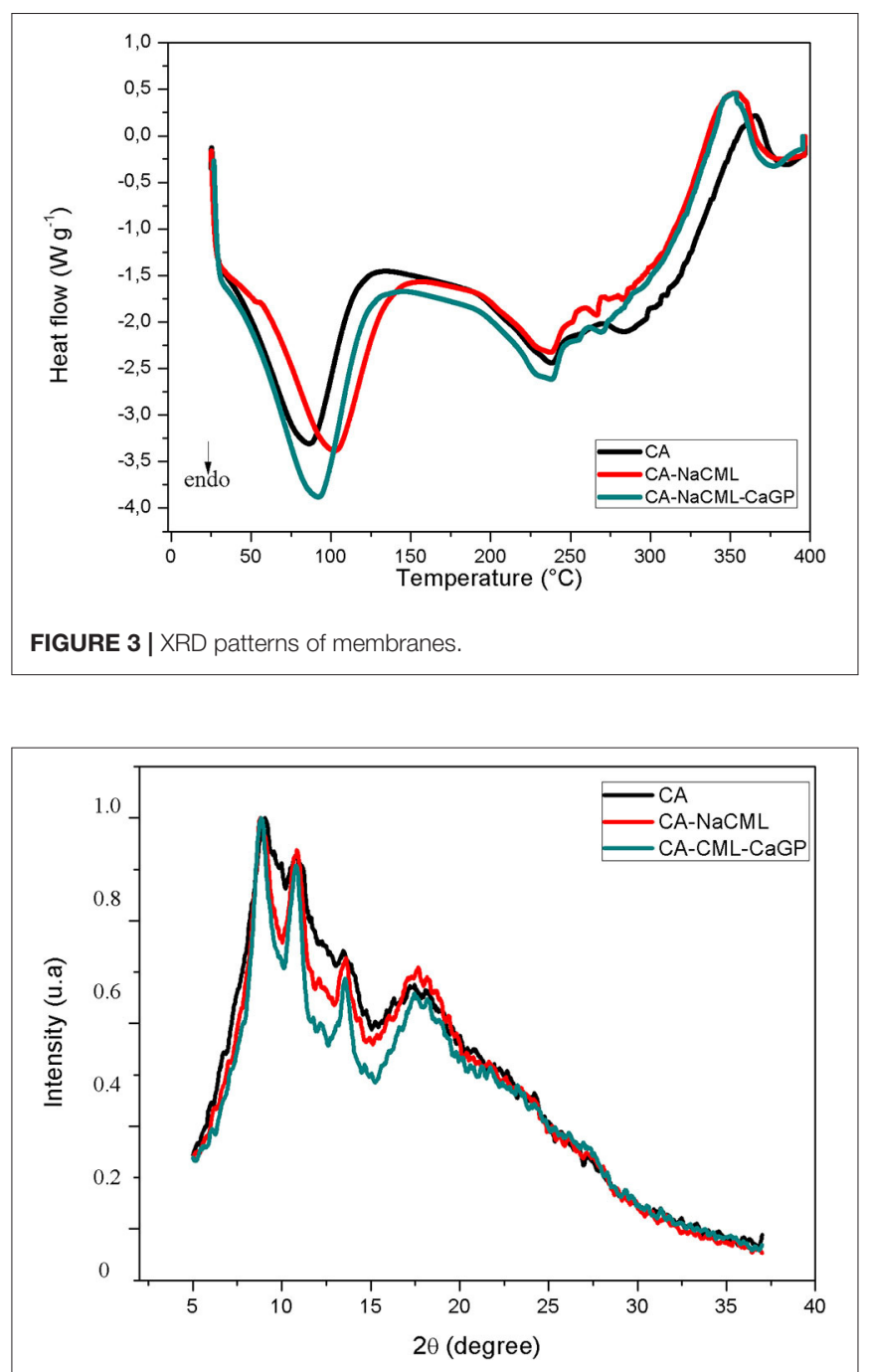

FIGURE 4 | DSC curves for the membranes.

TABLE 3 | Influence of the additives on the values of $\Delta H_{m}, T_{m}$ and percentage of crystallinity for the membranes.

\begin{tabular}{lccc}
\hline Sample & $\begin{array}{c}\Delta \mathbf{H}_{\mathbf{m}} \\
\left(\mathbf{J ~ g ~}^{-1} \mathbf{)}\right.\end{array}$ & $\begin{array}{c}\mathbf{T}_{\mathbf{m}} \\
\left({ }^{\circ} \mathbf{C}\right)\end{array}$ & $\%$ Crystallinity \\
\hline CA & $10.78 \pm 0.001$ & $237.54 \pm 0.001$ & $18.33 \pm 0.001$ \\
CA-NaCML & $12.80 \pm 0.001$ & $239.14 \pm 0.001$ & $21.77 \pm 0.001$ \\
CA-NaCML-CaGP & $13.69 \pm 0.001$ & $233.86 \pm 0.001$ & $23.28 \pm 0.001$ \\
\hline
\end{tabular}

degradation of cellulose acetate, which occurs at temperatures close to $235^{\circ} \mathrm{C}$.

The melting enthalpy values $\left(\Delta \mathrm{H}_{\mathrm{m}}\right)$, melt temperature $\left(\mathrm{T}_{\mathrm{m}}\right)$ and percentage crystallinity of the membranes are given in Table 3. After incorporating the additives, there is a small increase in the enthalpy of melting and increase of the crystallinity index, corroborating with the gain of the structural order of the membranes favored by the additives 

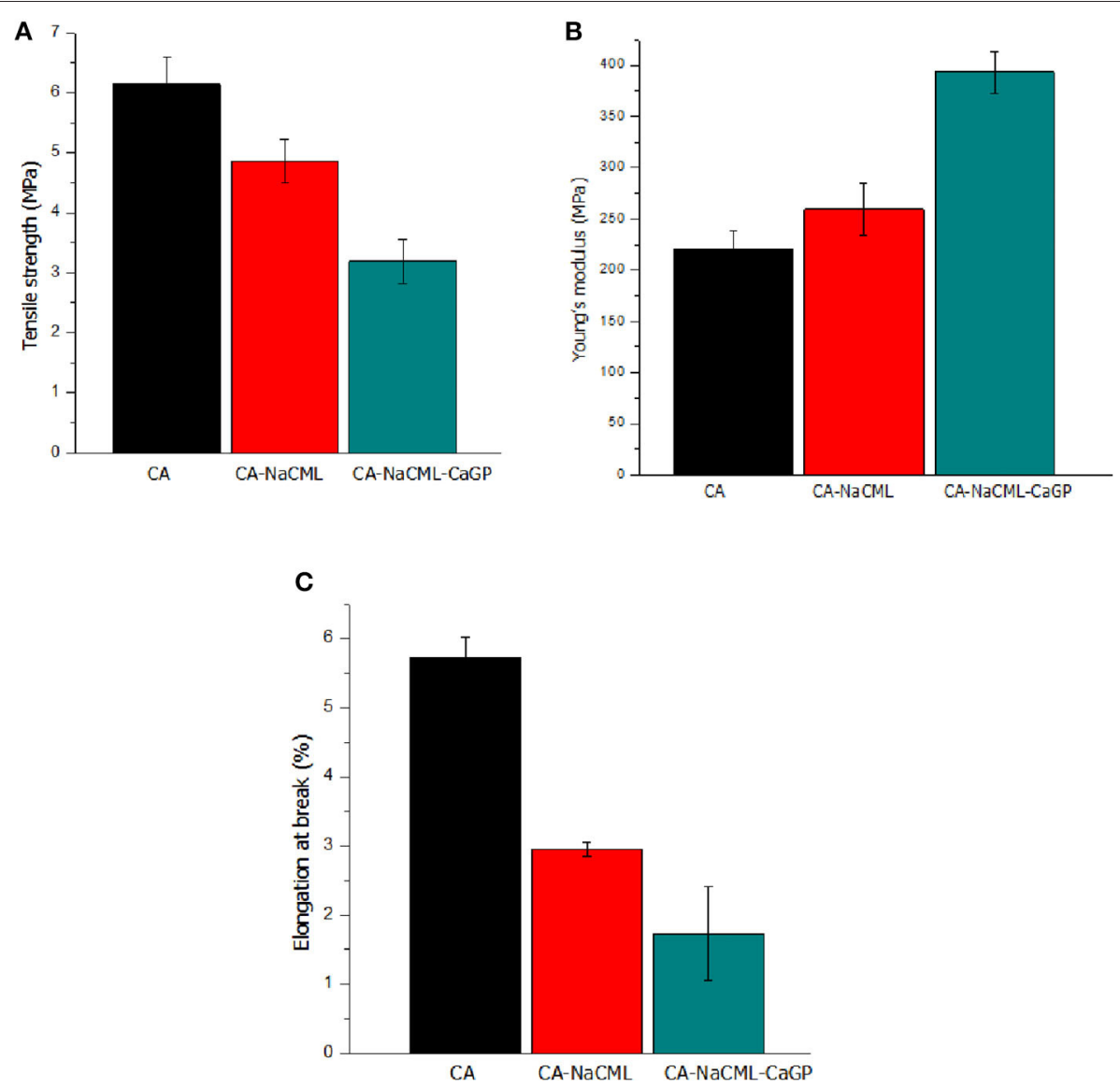

FIGURE 5 | Mechanical characteristics of the membranes (A) tensile strength, in MPa; (B) Young's modulus, in MPa; and (C) elongation at break, in \%.

\section{Mechanical Properties}

Figure 5 shows results of measurements of tensile strength, deformability and Young's modulus of the samples, which allows verifying the influence of additive incorporation. Membranes with additives, especially when incorporated with all (CANaCML-CaGP), showed a reduction in mechanical properties and an increase in stiffness (increase in Young's modulus) compared to pure membrane (CA).

\section{Swelling and Degradation Studies}

The swelling rate of the membranes for a period of up to $96 \mathrm{~h}$ is shown in Figure 6A. As can be seen, the incorporation of the additives does not alter the kinetics of swelling, its only increases the swelling ability.

\section{DISCUSSION}

The casting method is a simple and attractive technique for the development of membranes that could be used as physical barriers in periodontal regenerative processes. We have shown that CA membranes with appropriate additives can be easily obtained using a mixture of solvents, such as acetone and water, resulting in homogeneous samples with flexibility that allows easy handling. The membrane added with CML-Na showed small changes in thickness or density. On the other hand, the doubly additive membrane showed a very different behavior, with a significant increase in thickness and reduction in density. The increase in thickness (and apparently the crystallinity) can be explained by the insertion of calcium glycerophosphate between the polymer chains, increasing its porosity, as seen in the cross sections (SEM) of Figure 2. On the other hand, despite the large increase in membrane thickness and porosity, the 5\% decrease in density is considerable. One possible explanation for this is that there is an incompatibility between calcium glycerophosphate (and sodium carboxymethylignin) with cellulose acetate, which separates the polymer chains.

Both NaCML and CaGP increase the porosity of the CA membrane. These two additives are highly hygroscopic, unlike the CA matrix. The insertion of them in the CA matrix must, in a first effect, move away and reorganize the CA matrix in a new structure that supports these additives. The interaction of the organic parts of the additives with the matrix is an important factor. The increase in crystallinity observed by X-ray diffraction corroborates this effect.

The water present in the solvent (acetone) facilitates the solubilization of glycerophosphate and carboxymethylignin in 

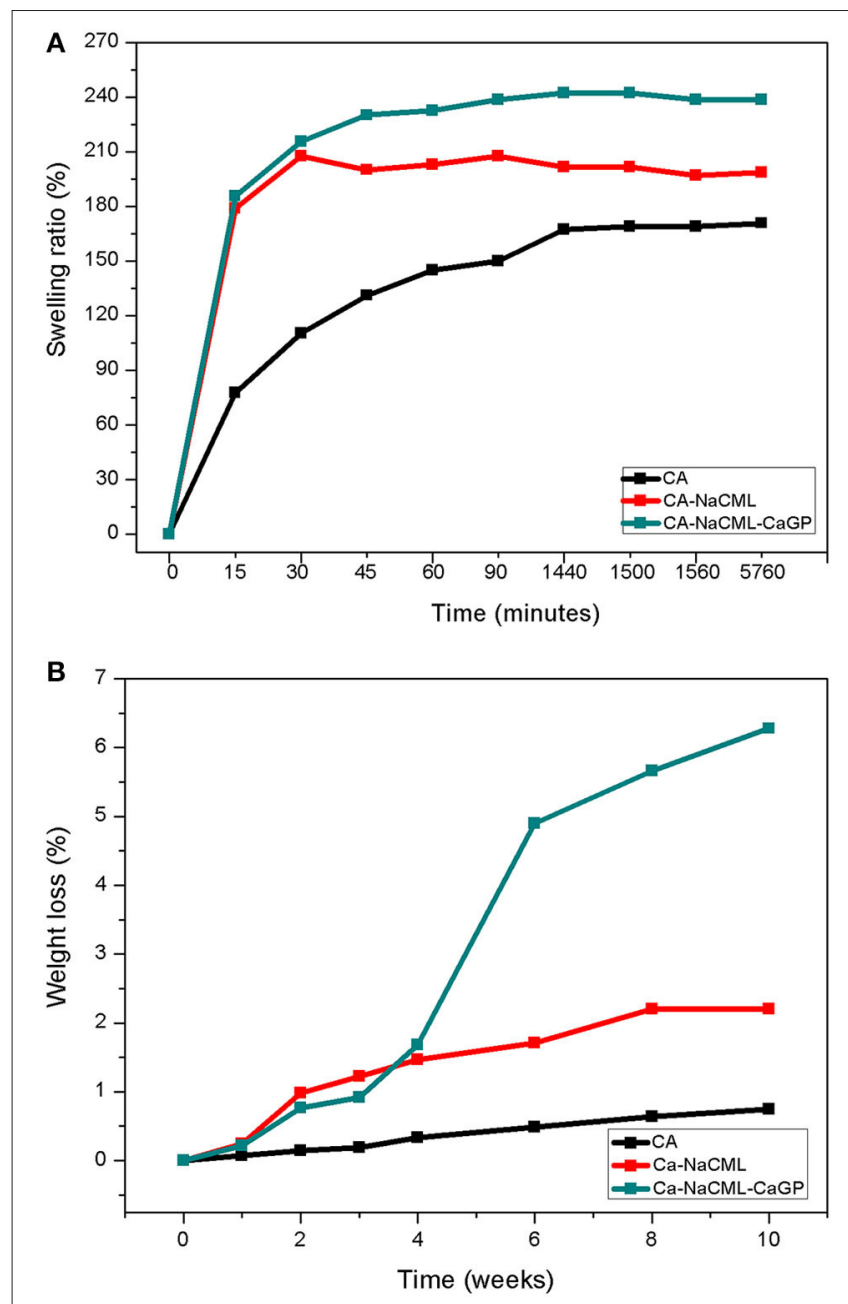

FIGURE 6 | (A) Swelling of the membranes over a period of $96 \mathrm{~h}$ and (B) Degradation profile in percent of weight loss of the membranes.

the polymer, but after the evaporation of the solvent mixture, it creates the pores seen in the micrographs of the fractures of the film. A confirmation of the structural alteration of cellulose acetate in the presence of the additives is the TG and DTA data shown in Supplementary Figure 1. In these data the changes caused by the addition of sodium carboxymethyl lignin and then by the addition of calcium glycerophosphate can be clearly seen.

Regarding the SEM images, the membranes show the presence of unevenly distributed non-uniform pores, which classify it as asymmetrical. These morphological observations are due to the type of processing used to develop the membranes, which involves the use of two solvents, which evaporate at different rates. In this case, acetone evaporates more rapidly than water promoting two effects: an increase in membrane coalescence time, leading to phase separation and increasing the concentration of water in the polymer structure, initially forming a gel phase. After the gelation process has taken place, the reduction of the volume of the solution is hampered by the more rigid structure formed by the gel. Thus, with the total evaporation of acetone, a porous membrane is obtained (21). In this case, due to the homogeneity of the mixture, a membrane with homogeneous porosity is formed. Unlike the pure membrane, when the additives are incorporated into the polymer matrix, there is an increase in porosity as a consequence of the different interactions between the membrane components and the solvent mixture. The NaCML interacts very strongly with water at $\mathrm{pH}$ above 4 which favors the formation of larger pores in the membrane, since water is the less volatile solvent and should last evaporate. However, CaGP has a strong attraction to both water and $\mathrm{NaCML}$ due to its polar structure, which greatly facilitates the formation of pores and explains the decrease in density observed in the membrane with two additives.

Still in relation to the SEM micrographs, we can say that the porosity is an important characteristic for use in regenerative processes, since the existence of pores in the structure of the membranes facilitate the diffusion of fluids, oxygen, nutrients, and bioactive substances for cell growth, which is vital for bone and soft-tissue regeneration (22). The pore size is closely related to the tissue's occlusion property and has a major influence on the invasion of soft tissue cells. Very large pores can negatively affect this membrane property, allowing undesirable soft tissue cells to migrate through it, overpopulate the defect site and inhibit the infiltration and activity of bone-forming cells (23, 24). As reported by Bartee (25), the presence of 5-30 $\mu \mathrm{m}$ pores in the expanded polytetrafluoroethylene (e-PTFE) membrane facilitates bacterial contamination and strong local soft tissue fixation. Considering that the pores of our cellulose acetate devices measure less than $4 \mu \mathrm{m}$, it can be concluded that its have a capacity for exclusion. The membranes diffractograms showed that the presence of additives did not significantly alter the diffraction profile of CA. But it favored the reorganization of the polymer chains of cellulose acetate, which somehow increased the crystallinity and decrease the density of the material. Despite the low concentration used of the additives, an important structural change in the membranes occurs.

Regarding the thermal behavior of the membranes, the incorporation of the additives did not promote significant changes in the measured melting temperature. Another notable fact is the increase in enthalpy of membrane fusion. Incorporating just $1 \% \mathrm{NaCML}$ into the membrane increases the heat of fusion by $16 \%$. In the incorporation of $0.41 \%$ of the calcium glycerophosphate the increase in the heat of fusion increases by $6.5 \%$. The addition of both simultaneously causes an increase of $21 \%$ in the heat of fusion. Despite the apparent incompatibility of the two organic salts with the cellulose acetate structure, its presence in the membrane matrix favors the increase in porosity, melt energy and crystallinity. Probably the organic part of the salts should favor its interactions with the matrix.

The results of the mechanical test show that membranes with additives show a reduction in properties such as tensile strength and deformation capacity when compared to pure membrane. This is due to the increase in the number and size of the pores, which is in accordance with the small variation in the density of these samples. We also observed an increase in Young's modulus, 
indicating an increase in membrane stiffness, corroborating the increase in sample crystallinity and greater porosity. In this case, as previously mentioned, the incorporation of $\mathrm{NaCML}$ and subsequent addition of $\mathrm{CaGP}$ seems to promote an increase in the stiffness between the cellulose acetate chains forming a structure less resistant to traction and deformation. As the biggest difference between the two organic salts is the ion charge $(\mathrm{Na}+$ and $\mathrm{Ca}++)$, an attractive interaction between them can be predicted, due to the membrane having been elaborated in solvent with $20 \%$ water. The attractive interaction between the phosphate group and sodium carboxymethyl lignin and sodium carboxymethyl cellulose, has already been demonstrated by us in a previous publication, biomass and bioenergy 35 (26) 3913-3919). The anionic organic portion of the two molecules has mainly phenolic and aliphatic $\mathrm{OH}$ groups in $\mathrm{NaCML}$, and aliphatic groups in CaGP. Despite being two organic salts, due to these structures, there is a compatibility between it and with the cellulose acetate matrix. It can further be said that the mechanical properties of the membranes with both additives are influenced not only by the higher porosity but also by the presence of larger portions of crystalline regions in the membrane structure resulted from the combination of the additives as shown by percentage values of crystallinity (Table 3 ).

The insertion of fillers NaCML and CaGP clearly increases the porosity of the CA matrix. The increase in porosity, however, is accompanied by a significant increase in crystallinity and heat of fusion, as seen in Table 3. In our studies $(11,27)$ we found that glycerol, organic part of CaGP, added to CA has an ambiguous behavior, depending on concentration. At low concentrations, it acts as a crosslinking agent, interacting to decrease the material's density. At high concentrations, however, it acts as a solvent, dissolving the acetate.

It is important to remember that an "ideal" periodontal membrane should balance two material properties, such as stiffness and elasticity, to support its own weight and resist the pressure exerted by the overlying tissue and external forces such as chewing without collapsing the membrane, in addition to maintaining a space suitable for regeneration. Considering that the force exerted by the teeth in the chewing process promotes a tension of 0.7 to $1.7 \mathrm{MPa}$ (28), we can consider that the membranes developed are strong enough to resist masticatory forces, maintaining the regenerative space.

The swelling rate is an important parameter in studies of polymer matrices, since it evaluates its capacity of absorption and retention of liquids. The swelling ability of membranes occurs by the spacing between the CA chains due to the retention of the molecules of the PBS solvent, which reduces the intermolecular attraction forces and increases the mobility of the chains. As the additives are incorporated, the swelling capacity increases, since it gives a certain hydrophilicity to the membrane, favoring a greater interaction between the membrane and PBS, which is largely composed of water. In addition, another aspect that affects swelling is the greater porosity of the additive membranes, which allows for increased swelling because it allows the trapping of more water molecules. On the other hand, this leads to a greater degradation process, as shown in Figure 6B.
In the mass loss study, used to evaluate the degradation profile of the samples, it was found that the presence of additives, while increasing the hydrophilicity of the membrane, did not induce a significant change in the rate of degradation, since during the analysis period the mass loss kinetics of the membranes was not very significant. Initially, during the first 15 minutes, the swelling rate increases rapidly for the 3 samples, but more markedly for the samples with the additives. In the sequence, the absorption kinetics is lower, tending to a plateau. Samples with additives reach a steady state after 30 minutes, with a swelling of approximately $198 \%$ for CA-NaCML and $238 \%$ for CA-NaCMLCaGP. While the CA sample continues to grow, it only reaches a plateau in $24 \mathrm{~h}$ with $170 \%$.

The membrane degradation profile at physiological $\mathrm{pH}$ is shown in Figure 6B. We can see a small initial weight loss, even in the presence of additives in the membrane. This fact is associated with the low water solubility of the AC used (due to its degree of substitution), which is the basis of the polymeric matrix of the elaborated membranes. However, after 4 weeks, the membrane with the 2 additives, starts to degrade more sharply, showing a constant linear kinetics above to 6 weeks. Because it is the application in periodontal regenerative treatments, the rate of degradation is an essential parameter, since when playing the role of physical barrier, the membrane must remain intact separating the bone tissue from the connective tissue, for 3 to 4 weeks, period this is necessary for a complete regeneration (29). Considering that the materials commonly suggested for this application are degraded by the hydrolysis process and are disturbed by the oral environment, the verification of a degradation process that does not promote tissue damage during treatment is one of the first characteristics required for these materials. In this way, the membranes produced meet the requirements to be used as a little physical barrier, or nonabsorbable, since they have a degradation process at long term.

\section{CONCLUSION}

This study demonstrated that cellulose acetate porous membranes can be developed by the casting method using a combination of two solvents and that the incorporating a low amount of $\mathrm{NaCML}$ and $\mathrm{CaGP}$, combined or not, can improve membrane interaction with the oral environment. Although the membranes have differentiated characteristics through a combination of the additives, its biocompatibility, mechanical properties, controllable degradation rate, make it an attractive material for use as a dental barrier membrane.

\section{DATA AVAILABILITY STATEMENT}

The raw data supporting the conclusions of this article will be made available by the authors, without undue reservation.

\section{AUTHOR CONTRIBUTIONS}

MF was responsible for the conceptualization, methodology, writing and revision of the manuscript. RR was responsible 
for the methodology and contributed to the writing and revision of the manuscript. HO, PG, DP, and GP contributed to the writing and revision of the manuscript. All authors contributed to the article and approved the submitted version.

\section{FUNDING}

This study was supported by Faculty of Civil Engineering for the technical support in traction analyzes and Multiuser Laboratory of the Institute of Chemistry of the Federal University of Uberlândia for the technical support in the characterizations.

\section{REFERENCES}

1. Socransky SS. Periodontal microbial ecology. Periodontology. (2005) 38:13587. doi: 10.1111/j.1600-0757.2005.00107.x

2. Kinane DF, Stathopoulou PG. Periodontal diseases. Nature Reviews Disease Primers. (2017) 3:1-14. doi: 10.1038/nrdp.2017.38

3. Caton JG, Greenstein G. Factors related to periodontal regeneration. Periodontology. (1993) 1:9-15. doi: 10.1111/j.1600-0757.1993.tb00202.x

4. Lee D, Lee SJ, Moon JH, Kim JH, Heo DN, Bang JB, et al. Preparation of antibacterial chitosan membranes containing silver nanoparticles for dental barrier membrane applications. J Ind Eng Chem. (2018) 66:196-202. doi: 10.1016/j.jiec.2018.05.030

5. Zhuang Y, Lin K. Avanço das fibras eletrofiadas nanocompósitos na regeneração periodontal. Fronteiras na química. (2019) 7:495. doi: 10.3389/fchem.2019.00495

6. Nyman S, Lindhe J, Karring T. New attachment following surgical treatment of human periodontal disease. J Clin Periodontol. (1982) 9:290-6. doi: 10.1111/j.1600-051X.1982.tb02095.x

7. Liang $Y$, Luan $X$. Recent advances in periodontal regeneration: a biomaterial perspective. Bioact Mater. (2020) 5:297-308. doi: 10.1016/j.bioactmat.2020.02.012

8. Iviglia G, Kargozar S. Biomaterials, current strategies, and novel nanotechnological approaches for periodontal regeneration. J Funct Biomater. (2019) 10:3. doi: 10.3390/jfb10010003

9. Ruggiero R, de Almeida Carvalho V, da Silva LG, de Magalhães D, Ferreira JA, Henrique $\mathrm{H}$, et al. Study of in vitro degradation of cellulose acetate membranes modified and incorporated with tetracycline for use as an adjuvant in periodontal reconstitution. Industrial Crops and Products. (2015) 72:2-6. doi: $10.1016 /$ j.indcrop.2015.03.021

10. Sam G. Evolution of barrier membranes in periodontal regeneration-are the third generation membranes really here? J Clin Diagn Res. (2014) 8:ZE14-7. doi: 10.7860/JCDR/2014/9957.5272

11. Gontijo de Melo P, Fornazier Borges M, Afonso Ferreira J, Vicente Barbosa Silva M, Ruggiero R. Bio-based cellulose acetate films reinforced with lignin and glycerol. Int J Mol Sci. (2018) 19:1143. doi: 10.3390/ijms190 41143

12. Carter SSD, Costa PF, Vaquette C, Ivanovski S, Hutmacher DW. Additive biomanufacturing: an advanced approach for periodontal tissue regeneration. Ann Biomed Eng. (2017) 45:12-22. doi: 10.1007/s10439-016$1687-2$

13. Arbade GK, Srivastava J, Tripathi V, Lenka N. Enhancement of hydrophilicity, biocompatibility and biodegradability of poly ( $\varepsilon$-caprolactone) electrospun nanofiber scaffolds using poly (ethylene glycol) and poly (L-lactide-co$\varepsilon$-caprolactone-co-glycolide) as additives for soft tissue engineering. $J$ Biomater Sci Polym Ed. (2020) 31:1648-70. doi: 10.1080/09205063.2020.17 69799

14. Wei L, Teng F, Deng L, Liu G, Luan M, Jiang J, et al. Periodontal regeneration using bone morphogenetic protein 2 incorporated biomimetic calcium phosphate in conjunction with barrier membrane: A pre-clinical study in dogs. J Clin Periodontol. (2019) 46:1254-63. doi: 10.1111/jcpe.13195

\section{ACKNOWLEDGMENTS}

The authors are very grateful to CAPES (Coordination of Improvement of Higher Education Personnel), FAPEMIG (Research Support Foundation of the State of Minas Gerais), CNPq (National Research Council).

\section{SUPPLEMENTARY MATERIAL}

The Supplementary Material for this article can be found online at: https://www.frontiersin.org/articles/10.3389/fdmed. 2021.776887/full\#supplementary-material
15. Qasim SB, Najeeb S, Delaine-Smith RM, Rawlinson A. Potential of electrospun chitosan fibers as a surface layer in functionally graded GTR membrane for periodontal regeneration. Dent Mater. (2017) 33:71-83. doi: 10.1016/j.dental.2016.10.003

16. Thevar JTK, Malek NANN. In vitro degradation of triple layered poly (lactic-co-glycolic acid) composite membrane composed of nanoapatite and lauric acid for guided bone regeneration applications. Mater Chem Phys. (2019) 221:501-14. doi: 10.1016/j.matchemphys.2018. 09.060

17. Cerrutti BM, de Souza CS, Castellan A, Ruggiero R, Frollini E. Carboxymethyl lignin as stabilizing agent in aqueous ceramic suspensions. Ind Crops Prod. (2012) 36:108-15. doi: 10.1016/j.indcrop.2011.08.015

18. Zhuang GL, Wey MY. The density and crystallinity properties of PPO-silica mixed-matrix membranes produced via the in situ solgel method for $\mathrm{H} 2 / \mathrm{CO} 2$ separation. II: Effect of thermal annealing treatment. Chem Eng Res Des. (2015) 104:319-32. doi: 10.1016/j.cherd.2015. 08.020

19. Cerqueira DA, Rodrigues Filho G. A new value for the heat of fusion of a perfect crystal of cellulose acetate. Polym. (2006) 56:475-84. doi: 10.1007/s00289-006-0511-9

20. Candido RG, Godoy GG. Characterization and application of cellulose acetate synthesized from sugarcane bagasse. Carbohydr Polym. (2017) 167:280-9. doi: 10.1016/j.carbpol.2017.03.057

21. Vaessen DM, McCormick AV, Francis LF. Effects of phase separation on stress development in polymeric coatings. Polymer. (2002) 43:2267-77. doi: 10.1016/S0032-3861(02)00042-3

22. Oh SH, Byun JH, Chun SY, Jang YJ. Plasmid DNA-loaded asymmetrically porous membrane for guided bone regeneration. J Mater Sci Technol. (2021) 63:161-71. doi: 10.1016/j.jmst.2020.03.015

23. Schmid J, Hämmerle CHF, Olah AJ. Membrane permeability is unnecessary for guided generation of new bone. An experimental study in the rabbit. Clin Oral Implants Res. (1994) 5:125-30. doi: 10.1034/j.1600-0501.1994.05 0302.x

24. Elgali I, Omar O, Dahlin C. Guided bone regeneration: materials and biological mechanisms revisited. Eur J Oral Sci. (2017) 125:315-37. doi: $10.1111 /$ eos. 12364

25. Bartee BK. The use of high-density polytetrafluoroethylene membrane to treat osseous defects: clinical reports. Implant Dent. (1995) 4:21-6. doi: 10.1097/00008505-199504000-00004

26. Carvalho WS, Martins DF, Gomes FR, Leite IR, da Silva LS, Ruggiero R., et al. Phosphate adsorption on chemically modified sugarcane bagasse fibres. Biomass Bioenergy. (2011) 35:3913-9. doi: 10.1016/j.biombioe.2011. 06.014

27. Rodrigues S. Preparo e caracterização in vitro de filmes de hidrogel de amido reticulado com glicerol visando aplicação em procedimentos regenerativos odontológicos 65 f Dissertação (Mestrado em Odontologia) - Faculdade Federal de Uberlândia, Uberlândia (2019).

28. Lima JJP. Introdução à Mecânica e a outros temas em Medicina Dentária. Imprensa da Universidade de Coimbra/Coimbra University Press (1999). p. 292. 
29. Da Silveira Gerzson A, Júnior PDR, Matsumoto MA, Duarte MA, Weckwerth PH. Barrier membranes for GBR: characteristics and indication. J Clin Dent Res. (2016) 13:120-5. doi: 10.14436/2447-911x.13.4.120125.oar

Conflict of Interest: The authors declare that the research was conducted in the absence of any commercial or financial relationships that could be construed as a potential conflict ofinterest.

Publisher's Note: All claims expressed in this article are solely those of the authors and do not necessarily represent those of their affiliated organizations, or those of the publisher, the editors and the reviewers. Any product that may be evaluated in this article, or claim that may be made by its manufacturer, is not guaranteed or endorsed by the publisher.

Copyright (๑) 2021 Fornazier, Gontijo de Melo, Pasquini, Otaguro, Pompêu and Ruggiero. This is an open-access article distributed under the terms of the Creative Commons Attribution License (CC BY). The use, distribution or reproduction in other forums is permitted, provided the original author(s) and the copyright owner(s) are credited and that the original publication in this journal is cited, in accordance with accepted academic practice. No use, distribution or reproduction is permitted which does not comply with these terms. 